\title{
Estimativas dos efeitos diretos e indiretos do retorno migratório no decênio de 2000 a 2010, no Seridó.
}

\author{
Ítalo Eduardo Brito da Costa ${ }^{1}$
}

Resumo

O Seridó potiguar é uma região do semiárido brasileiro que enfrenta, por causa das características ambientais, graves crises hídricas gerando nessa região um grande fator de expulsão na população. O trabalho tem como objetivo estimar o perfil dos migrantes de retorno dos efeitos direto e indiretos no Seridó potiguar. Logo, para entender um pouco as motivações do retorno para uma região semiárida, traçou-se o perfil dos retornados (efeitos diretos e indiretos). Foram empregados para a construção do trabalho os microdados do censo Demográfico do Instituto Brasileiro de Geografia e Estatística (IBGE) de 2010, e para as análises utilizou-se o Statiscal Package for the Social Sciences (SPSS). O perfil resultante das análises foram, em geral, pessoas em idade economicamente ativa, especificamente entre 14 e 34 anos, que moravam em Natal e migraram para Caicó, com baixo nível de escolarização, majoritariamente solteiros e mais da metade pertencente ao efeito direto de migração de retorno.

Palavras chave: Migração. Retorno. Efeitos. Direto. Indireto. Seridó. Migrantes.

Abstract

The Seridó potiguar is a region of the Brazilian semiarid that faces, due to the environmental characteristics, serious water crises giving to this region a great factor of expulsion in the population. The objective of this study is to estimate the profile of migrants returning from direct and indirect effects in Seridó potiguar. Therefore, to understand the motivations of the return to a semi-arid region, the profile of the returnees (direct and indirect effects) was traced. The microdata of the Demographic Census of Instituto Brasileiro de Geografia e Estatística (IBGE) of 2010 were used for the construction of the study and the Statistical Package for the Social Sciences (SPSS) was used for the analysis. At the end finding the profile of the return migrant for each effect and for both effects. The profile resulting from the analyzes were, generally, people of economically active age, specifically between 14 and 34 years old, who lived in Natal and migrated to Caico, with a low level of schooling, mostly single and more than half belonging to the direct effect of return migration

Keywords: Migration. Return. Effects. Direct. Indirect. Seridó. Migrants.

Introdução e Objetivo

A migração de retorno constitui-se como a volta para o local de nascimento após uma experiência (positiva ou negativa) em seu local de moradia (Ojima, Nascimento, 2014). Segundo Garcia e Ribeiro (2005) o retorno remete à saída do migrante de sua

\footnotetext{
${ }^{1}$ Graduando em Ciências Atuariais da Universidade Federal do Rio Grande do Norte (UFRN) Telefone: (84) 98873-6857, e-mail: italoactuar@gmai.com
} 
residência anterior e voltando para seu local de nascimento. Os últimos descrevem o retorno ida e volta, origem e destino fluxo e contrafluxo.

Esta modalidade de migração tem como motivação inúmeros fatores, que não serão discutidos na sequência, um deles é a experiência negativa, ou não, na adaptação no local da residência anterior ao do Censo, ou simplesmente um retorno dado que sua vida produtiva, no sentido mercadológico, cessou e tornou-se aposentado (Ribeiro, Carvalho, Wong, 1996).

Um outro motivo que pode ter favorecido à maior importância do retorno migratório para o nordeste foi o maior investimento e relativo desenvolvimento econômico da região experimentado ao longo das últimas décadas. Juntamente com um conjunto de políticas sociais, como por exemplo a aposentadoria rural, foram as responsáveis pelo crescimento dessa modalidade de migração (Araújo, 2000).

O estudo da migração de retorno é de suma importância, pois pode se tornar um fator importante para o crescimento demográfico ou, no caso do sertão nordestino, contribuir para a estagnação dos saldos migratórios negativos. No Paraná, os níveis verificados da migração de retorno foram elevados. 27,8\% dos imigrantes do Paraná entre o período de 70 a 80 eram de retorno (inclusos os efeitos diretos e indiretos). De 1981 a 1991 a proporção dos migrantes de retorno aumentaram consideravelmente, se comparado com o período de 70 a 80, chegando a 57,7\% dos imigrantes (Magalhães, 2003)

Em relação ao contexto geral do país, a migração de retorno representa cerca de $22 \%$ das migrações do período de 1995 a 2000 e 21,5\% dos migrantes de 2000 a 2005 (Ojima, Nascimento, 2014).

A migração de retorno tem dois efeitos: o direto e o indireto. O direto é quando os retornados são pessoas que nasceram no local onde residem no momento do Censo, porém havia morado em outro local anteriormente. $\mathrm{O}$ indireto pode ser dividido em duas partes: 1) os filhos dos migrantes retornados após o seu último movimento migratório e 2) as pessoas que não nasceram no local do retornado, mas migraram juntamente com o retorno de um dos membros do núcleo familiar.

Objetiva-se traçar e fazer a análise do perfil do migrante de retorno direto e indireto na região do Seridó potiguar, já que as características socioambientais da região 
tende a expulsão da população. A análise dos aspectos migratórios será exclusiva do decênio relativo ao Censo Demográfico de 2010.

Metodologia

Existem algumas metodologias para a estimação da migração de retorno e seus efeitos diretos e indiretos. De forma geral, a maioria dos autores sugerem fazer uma estimação dos efeitos indiretos através da relação de parentesco com o migrante de retorno, já que não necessariamente um residente do domicílio seria fruto de um efeito indireto.

Algumas metodologias que podem ser utilizadas para a análise são as sugeridas por Magalhães (2003); Ribeiro, Carvalho e Wong (1996); Garcia, Ribeiro (2005); Ribeiro, Carvalho (1999). A utilizada para este trabalho foi a de Ribeiro e Carvalho (1999). Será considerado para os efeitos diretos:

- O retorno para o município de nascimento.

- O retorno para o município, mesmo que não o de nascimento, mas para a mesma região (Seridó Potiguar)

Já para os efeitos indiretos são:

- Os imigrantes não naturais que residiam em domicílios de chefes retornados, independentemente do tempo de residência no local.

- Nos domicílios chefiados por não retornados, os imigrantes não naturais que possuem tempo de residência igual ou menor que o do retornado.

As variáveis utilizadas para essa estimação foram "Nasceu neste município", "Código de município anterior", "Controle", "Tempo de Residência".

É importante estar ciente que a proporção I e II consideradas na tabela 2 e 3 são razões do número de migrantes de determinada localidade pela população total do Seridó, para Proporção I, e quando o denominador é o total de imigrantes do Seridó é Proporção II.

Resultados

Geral (efeito direto e indireto): 
A imigração no Seridó, de última etapa, atingiu um total de 17.759 migrantes, já a migração de retorno, inclusos efeitos diretos e indiretos, 6.472. Em termos de porcentagem os imigrantes de retorno representam cerca de $36,4 \%$ do total de imigrantes. Isso reafirma o pensamento já citado de Magalhães (2003) que os migrantes de retorno têm uma importante contribuição no fator de saldo migratório de algumas regiões.

Iniciando a análise do perfil desse migrante, podemos perceber que eles são majoritariamente urbanos. Cerca 94\% desses moram na parte urbana da cidade, enquanto apenas 6\% na área rural. Enquanto os não migrantes do Seridó possuem um perfil levemente antagônico, pois apenas 60\% vivem em áreas urbanas e 40\% nas rurais.

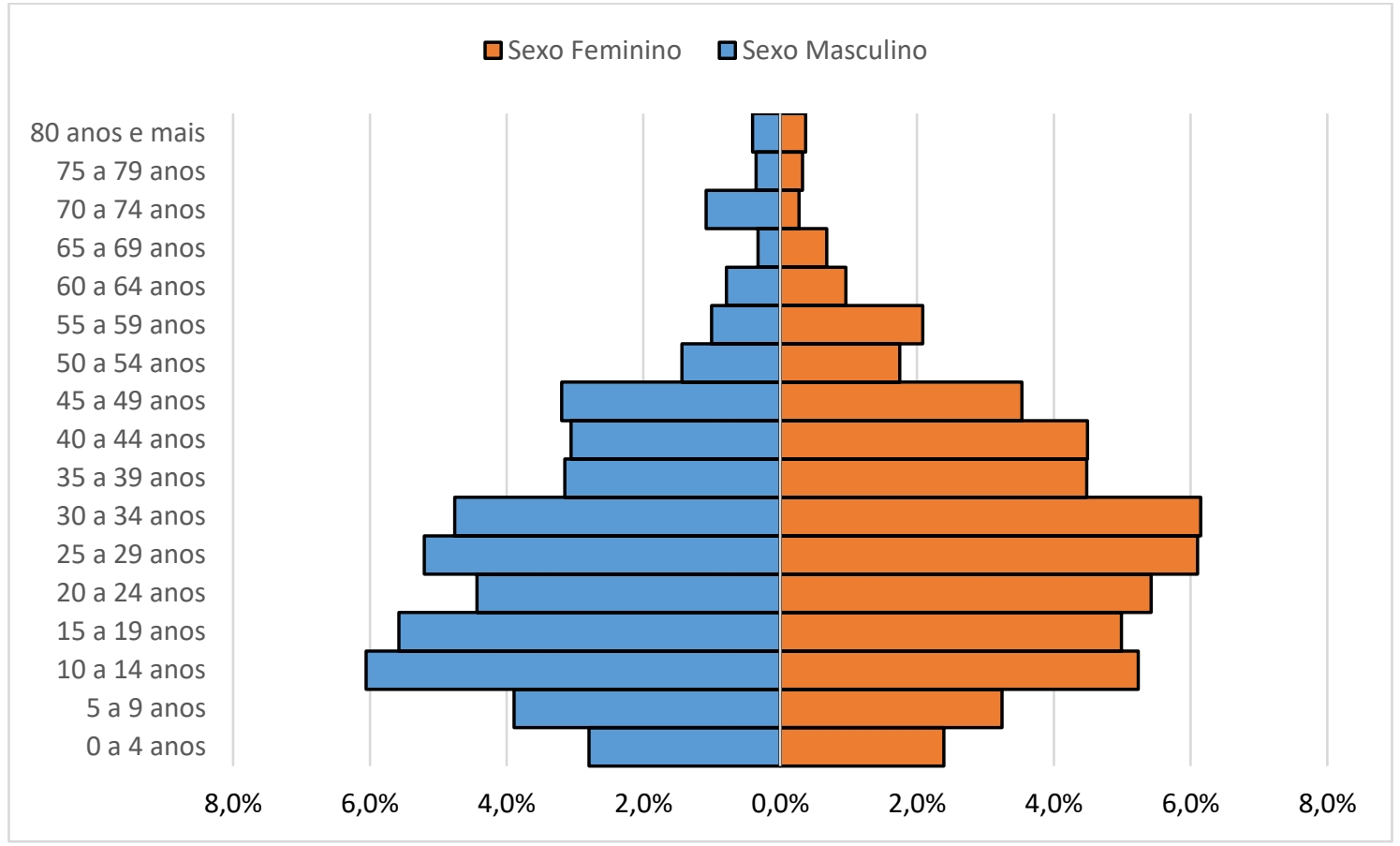

Figura 1: Pirâmide etária migrantes de retorno direto e indireto, migrantes de última etapa, 2010, Seridó. Fonte: Censo Demográfico 2010

Referente a estrutura etária da população de retornados (diretos e indiretos) temos uma pirâmide etária com uma concentração nas idades nas idades centrais da pirâmide, ou seja, pessoas em idade economicamente ativa. Há uma concentração dessa população entre as idades de 14 e 34 que juntas representam o total de quase 54\% da população. Diferente de uma das hipóteses levantadas anteriormente, a do retorno do aposentado ao seu local de origem. Aplica-se, neste caso, uma das conclusões de Golgher (2004) sobre a seleção dos migrantes em relação as idades. Observa-se, também, uma masculinização nas idades mais avançadas. Esse fenômeno ocorre principalmente na faixa etária dos 70 aos 74 anos. 
Dados importantes a serem observados são os indicadores de migração. Esses indicadores nos mostram a realidade migratória do local. Temos saldo migratório negativo que significa que a região perde mais pessoas do que ganha. Derivado desse saldo negativo possuímos outros dois indicadores negativos a taxa líquida de migração e o índice de eficiência migratória. Com isso podemos confirmar a tendência do local em ser expulsor de população.

Tabela 1: Informações sobre a migração, última etapa, no Seridó, 2010, Seridó.

\begin{tabular}{cc}
\hline Indicadores & Valores \\
\hline População no ano de 2010 & $216.508,0$ \\
Imigrantes & $17.759,0$ \\
Emigrantes & $22.809,0$ \\
Saldo migratório & $-5.050,0$ \\
Migração Bruta & $40.568,0$ \\
Taxa Líquida de migração & $-2,3 \%$ \\
Índice de eficiência migratória & $-12,4 \%$ \\
\hline
\end{tabular}

Fonte: IBGE, Censo Demográfico 2010.

Em relação a escolaridade é perceptível a tendência a baixa instrução. Percentualmente aproximadamente $55 \%$ não possui nenhum tipo de instrução ou fundamental incompleto. E quase 15\% fundamental completo e médio incompleto. Em valores aproximados quase $70 \%$ da população tem sua instrução máxima de fundamental completo.

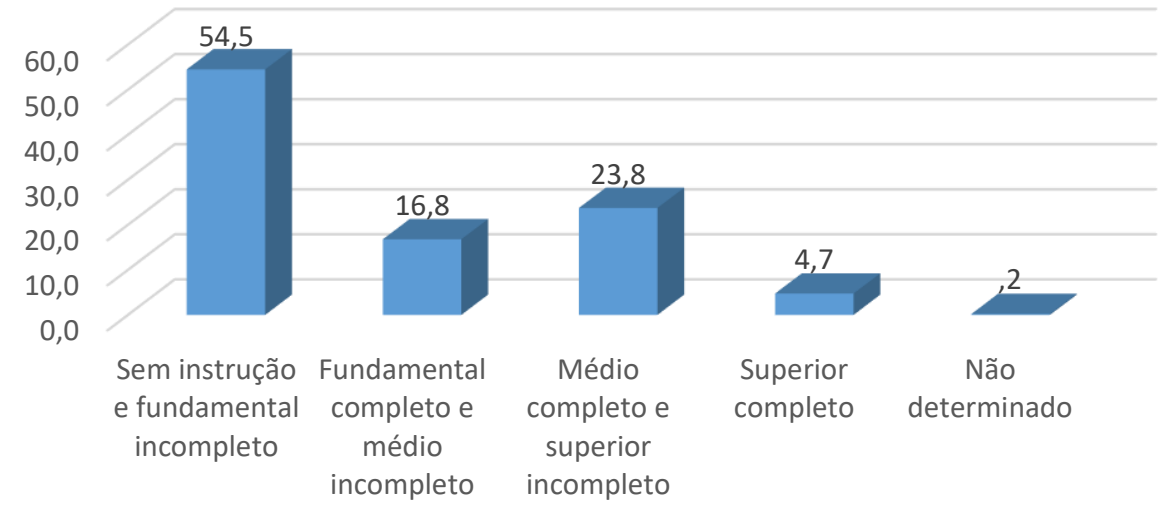

Figura 2: Nível de instrução migrantes de retorno, de última etapa, direto e indireto em porcentagem, 2010, Seridó Fonte: IBGE, Censo Demográfico 2010.

A cidade anterior ao retorno com maior volume de pessoas é Natal que soma $26,7 \%$ do total e em segundo lugar São Paulo com 4,2\% e seguido por Rio de Janeiro com 3,7\%. Em um levantamento de hipótese, pode-se dizer que este indivíduo jovem após um "fracasso" migratório na região retorna para sua cidade natal. A partir dessa afirmação 
também podemos dizer que a evolução migratória, por etapas, foi interrompida. A migração por etapas é o fenômeno de migração como uma cadeia evolutiva seguida pelo migrante. Inicia-se a vida em uma cidade pequena, muda-se para uma cidade média em buscas de oportunidades e finalmente vai para uma cidade maior com os mesmos objetivos (Golgher, 2004).

Tabela 2: Municípios de residência anterior dos migrantes de retorno, de última etapa, do efeito direto e indireto, 2010, Seridó

\begin{tabular}{|c|c|c|c|c|c|}
\hline Município & $\begin{array}{c}\text { Frequência } \\
\text { absoluta }\end{array}$ & $\begin{array}{l}\text { Frequência } \\
\text { relativa }\end{array}$ & $\begin{array}{c}\text { Frequência relativa } \\
\text { acumulada }\end{array}$ & Proporção I & Proporção II \\
\hline Natal & 1.727 & $26,70 \%$ & $26,70 \%$ & $0,80 \%$ & $9,72 \%$ \\
\hline São Paulo & 272 & $4,20 \%$ & $30,90 \%$ & $0,13 \%$ & $1,53 \%$ \\
\hline $\begin{array}{l}\text { Rio de } \\
\text { Janeiro }\end{array}$ & 241 & $3,70 \%$ & $34,60 \%$ & $0,11 \%$ & $1,36 \%$ \\
\hline Uberlândia & 177 & $2,70 \%$ & $37,30 \%$ & $0,08 \%$ & $1,00 \%$ \\
\hline Brasília & 148 & $2,30 \%$ & $39,60 \%$ & $0,07 \%$ & $0,83 \%$ \\
\hline $\begin{array}{l}\text { Parnamiri } \\
\mathrm{m}\end{array}$ & 127 & $2,00 \%$ & $41,60 \%$ & $0,06 \%$ & $0,72 \%$ \\
\hline Rio Verde & 102 & $1,60 \%$ & $43,20 \%$ & $0,05 \%$ & $0,57 \%$ \\
\hline Recife & 101 & $1,60 \%$ & $46,30 \%$ & $0,05 \%$ & $0,57 \%$ \\
\hline $\begin{array}{l}\text { João } \\
\text { Pessoa }\end{array}$ & 97 & $1,50 \%$ & $47,80 \%$ & $0,04 \%$ & $0,55 \%$ \\
\hline Fortaleza & 94 & $1,50 \%$ & $49,20 \%$ & $0,04 \%$ & $0,53 \%$ \\
\hline Pombal & 90 & $1,40 \%$ & $50,60 \%$ & $0,04 \%$ & $0,51 \%$ \\
\hline Outros & 3195 & $49,40 \%$ & $100,00 \%$ & $1,48 \%$ & $17,99 \%$ \\
\hline IGNORADO & 101 & $1,60 \%$ & $44,7 \%$ & $0,05 \%$ & $0,57 \%$ \\
\hline
\end{tabular}


Não diferente do esperado a maior parte dos migrantes moravam em 2010 nos municípios de Caicó e Currais Novos. Estas duas cidades são polos com maiores poderes econômicos que exercem uma grande influência política nas demais cidades da região. Logo, sabendo da influência politica-econômica dessa cidade nas demais, já era esperado tal acontecimento. Com os índices de proporções podemos verificar que a pesar do tamanho de algumas cidades pequenas, como parelhas e cruzeta, elas apresentaram uma proporção considerável se comparada as cidades maiores, sendo assim indicando uma preferência migratória, também para esses municípios.Podemos verificar isto na tabela 3.

Tabela 3: Municípios de residência em 2010 dos migrantes de retorno, de última etapa, do efeito direto e indireto, Seridó.

\begin{tabular}{|c|c|c|c|c|c|}
\hline Município & $\begin{array}{l}\text { Frequência } \\
\text { Absoluta }\end{array}$ & $\begin{array}{l}\text { Frequência } \\
\text { Relativa }\end{array}$ & $\begin{array}{l}\text { Frequência } \\
\text { Relativa } \\
\text { acumulada }\end{array}$ & Proporção I & Proporção II \\
\hline Caicó & 1.999 & $30,90 \%$ & $30,90 \%$ & $0,92 \%$ & $11,26 \%$ \\
\hline $\begin{array}{l}\text { Currais } \\
\text { Novos }\end{array}$ & 1.258 & $19,40 \%$ & $50,3 \%$ & $0,58 \%$ & $7,08 \%$ \\
\hline Parelhas & 871 & $13,50 \%$ & $63,80 \%$ & $0,40 \%$ & $4,90 \%$ \\
\hline Cruzeta & 441 & $6,80 \%$ & $70,60 \%$ & $0,20 \%$ & $2,48 \%$ \\
\hline $\begin{array}{l}\text { Jardim do } \\
\text { Seridó }\end{array}$ & 291 & $4,50 \%$ & $75,10 \%$ & $0,13 \%$ & $1,64 \%$ \\
\hline $\begin{array}{l}\text { São João } \\
\text { do Sabugi }\end{array}$ & 280 & $4,30 \%$ & $79,40 \%$ & $0,13 \%$ & $1,58 \%$ \\
\hline $\begin{array}{l}\text { Carnaúba } \\
\text { dos } \\
\text { Dantas }\end{array}$ & 268 & $4,10 \%$ & $83,60 \%$ & $0,12 \%$ & $1,51 \%$ \\
\hline $\begin{array}{l}\text { Jardim de } \\
\text { Piranhas }\end{array}$ & 222 & $3,40 \%$ & $87,00 \%$ & $0,10 \%$ & $1,25 \%$ \\
\hline Acari & 197 & $3,00 \%$ & $90,00 \%$ & $0,09 \%$ & $1,11 \%$ \\
\hline Outros & 645 & $10,00 \%$ & $100,00 \%$ & $0,30 \%$ & $3,63 \%$ \\
\hline
\end{tabular}

Fonte: IBGE, Censo Demográfico 2010

As políticas de transferência de renda para esses migrantes têm uma certa importância. Apesar de não ser maioria, 23\% deles recebem algum tipo de renda originada 
dessas políticas públicas (derivadas do INSS, Programa de Bolsa Família e outros). Em contrapartida a maioria, $65 \%$ dessas pessoas, não recebem algum tipo de política. Os $12 \%$ restante são crianças, logo, desconsideradas para efeito desta análise.

Ao analisar as ocupações desses migrantes percebeu-se um contingente considerável de militares. Aproximadamente $10 \%$ dos casos válidos, ou seja, que responderam a pergunta de ocupação, são militares. Essa porcentagem representa quase 5\% da população dos migrantes de retorno. Uma suposição para essa quantidade de migrantes retorno seria os planos de movimentação de militares das instituições estatais, já que os militares, tem que se movimentar no território de jurisdição do ente federativo que o emprega.

Quando segregamos esses militares dos demais podemos encontrar algumas coisas interessantes. A maior proporção desses migrantes não moram nas cidade de maior influência econômica e política da região, Caicó e Currais novos, que juntos somam apenas $30 \%$ da população dos militares, já cidades menores como Cruzeta e Parelhas juntas somam $47 \%$ do total dessa população. Essas pessoas em sua maioria são mulheres, cerca de 58\%, considerando que nas organizações militares elas são minoria esse fato é importante para essa população. Existe também uma masculinização da população em idades entre 17 e 18 anos, aparentemente, isso deve-se ao alistamento militar obrigatório. Além disso possuem rendas maiores que a população em geral com média 1,3 salários mínimos.

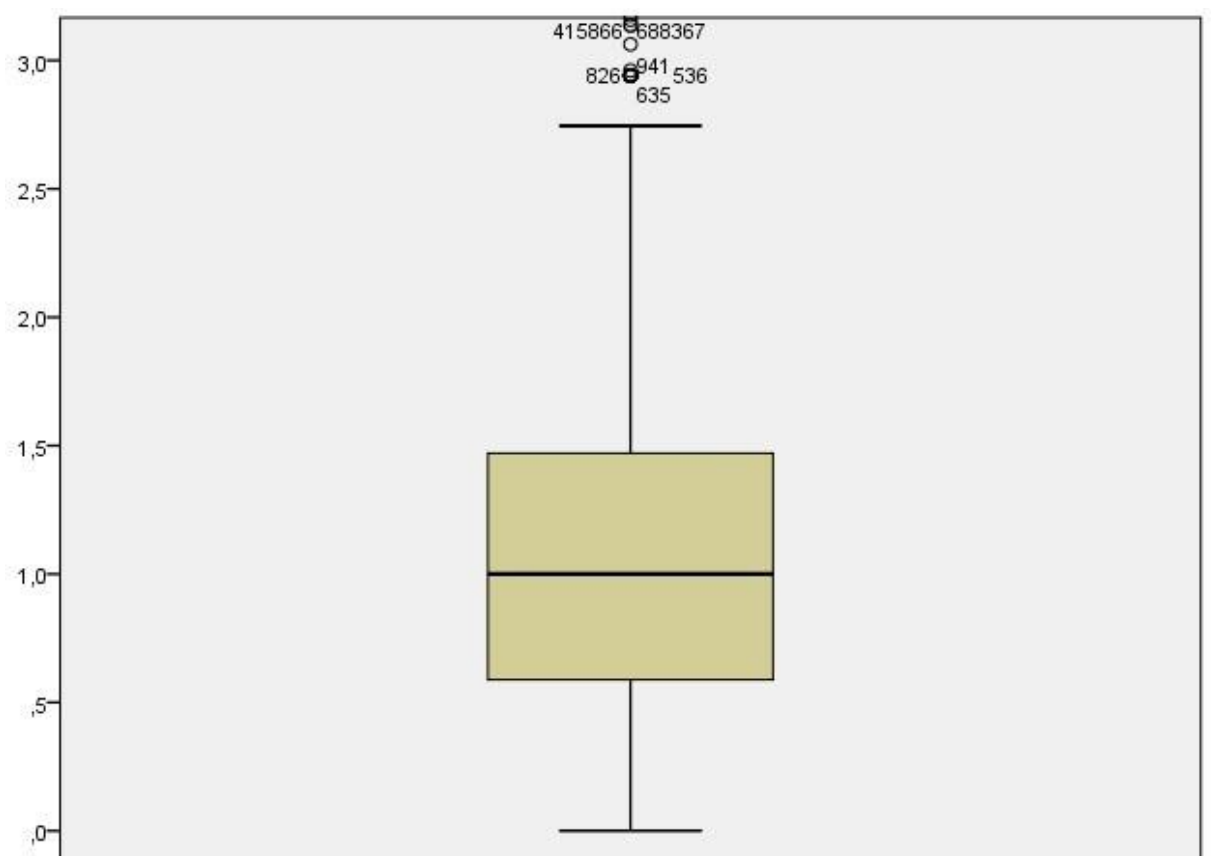

Figura 3: Gráfico boxplot de Renda em todos os trabalhos em números de salários mínimos dos migrantes de retorno, de última etapa, para ambos os efeitos migratórios, 2010, Seridó. Fonte: IBGE, Censo Demográfico 2010. 
O gráfico acima nos revela a realidade financeira dos migrantes. Os migrantes recebem em média um salário mínimo e cerca de $75 \%$ da população recebe no máximo 1,5 salários. Podemos ver no gráfico alguns outliers, ou seja, valores aberrantes que não seguem os padrões estatísticos estabelecidos pelo gráfico boxplot. Isso significa que alguns indivíduos desse universo ganha muito acima dos desvios padrões estabelecidos pela estatística acima.

Tabela 4: Estado civil dos migrantes de retorno, de última etapa, efeito direto e indireto, 2010, Seridó

\begin{tabular}{cccc}
\hline Estado Civil & $\begin{array}{c}\text { Frequência } \\
\text { Absoluta }\end{array}$ & $\begin{array}{c}\text { Frequência } \\
\text { Relativa }\end{array}$ & $\begin{array}{c}\text { Frequência } \\
\text { Relativa } \\
\text { acumulada }\end{array}$ \\
\hline Solteiro(a) & 3528 & $54,5 \%$ & $54,5 \%$ \\
Casado(a) & 1733 & $26,8 \%$ & $81,3 \%$ \\
Viúvo(a) & 161 & $2,5 \%$ & $83,8 \%$ \\
Desquitado(a) ou separado(a) judicialmente & 134 & $2,1 \%$ & $85,8 \%$ \\
Divorciado(a) & 118 & $1,8 \%$ & $87,7 \%$ \\
Crianças & 798 & $12,3 \%$ & $100,0 \%$ \\
Subtotal (excluso as crianças) & 5674 & $87,7 \%$ & - \\
Total & 6472 & $100,0 \%$ & - \\
\hline
\end{tabular}

Fonte: IBGE, Censo Demográfico 2010

Os migrantes de retorno são, também, em sua maioria solteiros. Os pertencentes a este grupo representam $54,5 \%$ do total dos migrantes, já em segundo lugar vem os casados que representam $26,8 \%$. Isso pode explicar o motivo dos migrantes de retorno direto ser consideravelmente maior que os do efeito indireto, já que, como já explicado na metodologia, os últimos migram por causa dos primeiros. Os migrantes retornados de efeito direto na população de migrantes de retorno dos retornados representam $66 \%$. Enquanto o efeito indireto fica com os restantes 34\%. Percebemos, então, que nenhum dos efeitos podem ser desconsiderados, já que possuem um grande peso, apesar do efeito direto ser $32 \%$ maior que o indireto.

Avaliado foi, também, se os migrantes estavam empregados na semana de 25 a $31 / 07 / 2010$, em outras palavras, se o indivíduo trabalhou pelo menos uma hora em troca de dinheiro, produtos, mercadoria ou benefícios. Verificou-se, então, que que $53 \%$ da população não trabalhou nesse período contra $46 \%$ que exerceu algum tipo de trabalho em troca de alguma vantagem. Para este resultado foram desconsideradas as crianças. 


\section{Efeito Direto:}

Segundo a tabela 5 podemos perceber que as principais classes que esses migrantes de retorno de efeito direto se encaixam são os membros do núcleo familiar, ou seja, responsável pelo domicílio, o cônjuge e seus filhos. Essas classes representam 85\% do total dos migrantes de retorno, considerando a classe enteado. Apesar de não ser tão influenciável vemos que os não parentes representam aproximadamente $5 \%$ dos migrantes desse efeito, estes representados na tabela pela classe outros.

Em relação a estrutura etária desse efeito do retorno nós possuímos uma pirâmide similar a pirâmide geral, mas apresenta uma maior concentração de pessoas nas idades economicamente ativas, além de ser uma população mais velha que a analisada anteriormente. Estes indivíduos também são majoritariamente do sexo feminino. Na pirâmide que representa o universo completo dos migrantes de retorno, podemos visualizar uma população um pouco mais jovem que do efeito direto. Estas pessoas possuem uma média de idade igual a mediana que é dos 30 a 34 anos de idade.

Tabela 5: Grau de parentesco dos migrantes de retorno, de última etapa, efeito direto, 2010, Seridó.

\begin{tabular}{cccc}
\hline Grau de parentesco & Frequência & Frequência & \multicolumn{2}{c}{$\begin{array}{c}\text { Frequência } \\
\text { Relativa } \\
\text { Relativa }\end{array}$} & $\begin{array}{c}\text { Reluta } \\
\text { acumulada }\end{array}$ \\
\hline Pessoa responsável pelo domicílio & 1536 & $35,7 \%$ & $35,7 \%$ \\
Cônjuge ou companheiro (a) de sexo diferente & 844 & $19,6 \%$ & $55,3 \%$ \\
Filho (a) do responsável e do cônjuge & 682 & $15,8 \%$ & $71,1 \%$ \\
Filho (a) somente do responsável & 451 & $10,5 \%$ & $81,6 \%$ \\
Neto (a) & 161 & $3,7 \%$ & $85,3 \%$ \\
Enteado (a) & 148 & $3,4 \%$ & $88,8 \%$ \\
Irmão ou irmã & 112 & $2,6 \%$ & $91,4 \%$ \\
Convivente & 93 & $2,2 \%$ & $93,5 \%$ \\
Genro ou nora & 71 & $1,6 \%$ & $95,2 \%$ \\
Pai, mãe, padrasto, madrasta sogro ou sogra & 26 & $0,1 \%$ & $95,3 \%$ \\
& 208 & $4,7 \%$ & $100,0 \%$ \\
\hline
\end{tabular}

Fonte: IBGE, Censo Demográfico 2010

Verificou-se, também, uma tendência no crescimento da escolaridade desse grupo. Não há uma diferença de grande impacto, porém existe uma tímida diferença em todos os níveis de escolaridade. Fundamental completo subiu dois pontos percentuais, médio completo três pontos percentuais, nível superior completo um ponto percentual, e além disso uma queda de cinco pontos percentuais na população sem nenhum tipo de instrução. 
Podemos ver que por representar a maior parte da população dos retornados este grupo apresenta as características tendendo as características gerais da população. Em outras palavras, a análise da população de retornados representa bem este grupo. Outro exemplo desta tendência se mostra quando analisamos o estado civil, pois esses indivíduos apresentam os mesmos valores da análise de estado civil já posta aqui do outro grupo. Os valores dos rendimentos também apresentam a mesma tendência.

\section{Efeito Indireto:}

Podemos observar na figura 4 que uma pirâmide totalmente diferente da população geral. Esse grupo apresenta uma idade média de 20 a 24 anos, todavia a mediana, ou seja, metade da população está abaixo tem idade menor que 19 anos. A tabela utilizada para construção dessa pirâmide nos mostra, também, que um pouco mais da metade deles são do sexo masculino, porém entre as idades de 30 e 39 anos é claramente perceptível o crescimento do número de mulheres, sendo superior ao número de homens.

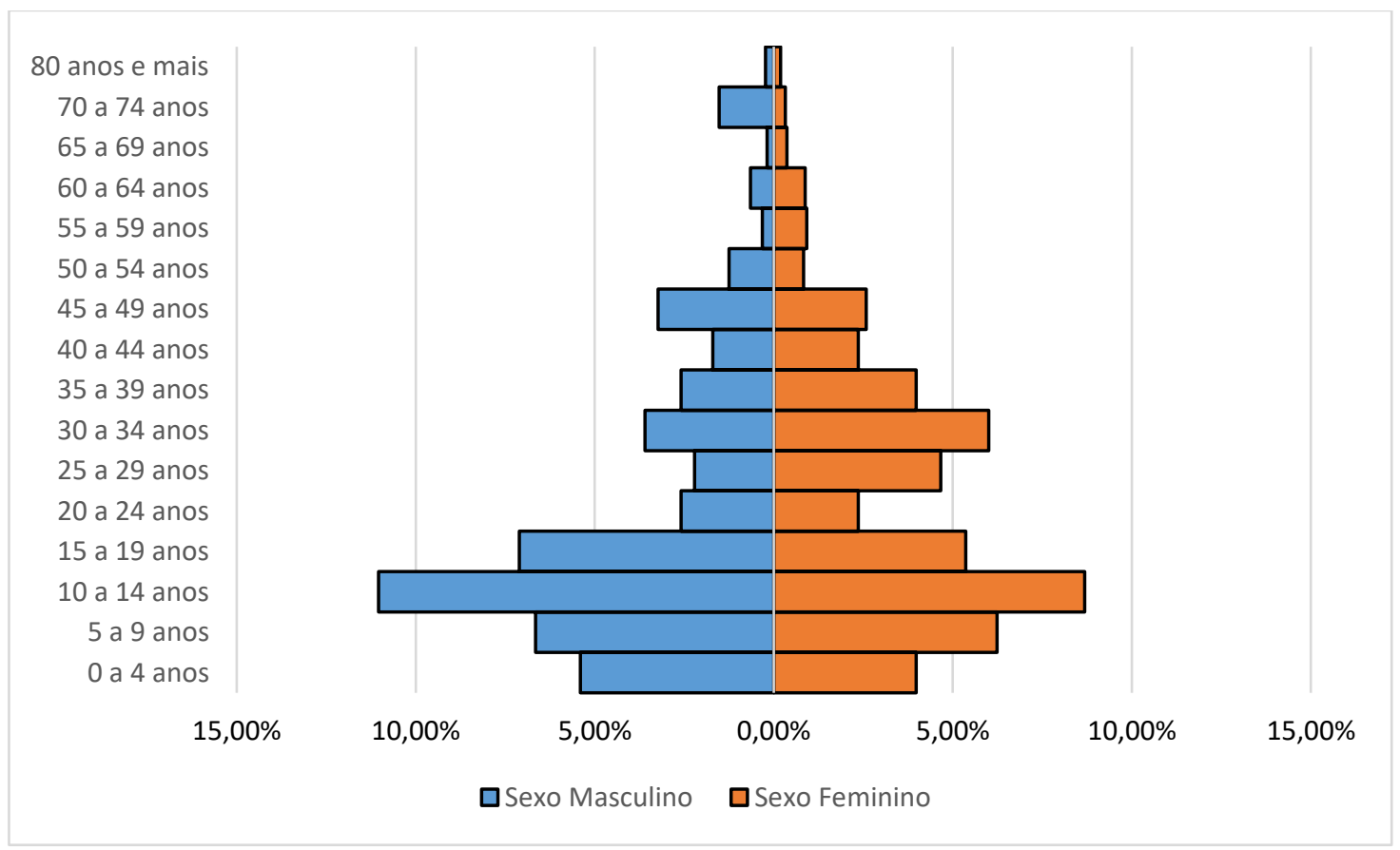

Figura 4: Pirâmide etária migrantes de retorno, de última etapa, efeito indireto, 2010, Seridó. Fonte: IBGE, Censo Demográfico 2010.

Olhando o grau de parentesco de efeito indireto, tabela 6, percebemos que as pessoas de maiores contingentes são as pertencentes as classes de filhos e cônjuge e a pessoa responsável pelo domicílio só vai aparecer em terceiro lugar com $18 \%$ do total desse efeito migratório. Portanto nesse ponto da análise percebemos um pouco da 
diferença dos perfis migratório de cada modalidade de migração, porém mesmo assim o responsável pelo domicilio ainda continua sendo uma das classes mais importantes da análise. Pode-se verificar, também, que apesar de ser o responsável ele pode ser fortemente influenciado pelos movimentos migratórios de seus familiares.

O nível de escolarização das pessoas desse efeito é muito mais baixo que o efeito geral e o efeito direto, porém pode ser facilmente justificado já que a população é muito mais jovem que as demais. Todavia, os resultados não deixam de ser interessantes, pois considerando que pessoas desse grupo tem idade média entre 20 e 24 e mesmo assim $64 \%$ da população não possui instrução ou fundamental incompleto. Apesar disso, constatou-se, também, que existem mais pessoas com nível médio completo e superior incompleto do que pessoas com fundamental completo e médio incompleto.

Considerando os rendimentos e outras frequências estatísticas observou-se, assim como no grupo do efeito direto, que os resultados não diferem muito do resultado geral nem do grupo de efeito direto. Esse grupo assim como nos outros mostrou um grande peso da população solteira seguida pela casada. Já nos níveis de rendimentos são extremamente próximos os valores dos grupos possuindo medianas e quartis parecidos.

Tabela 6: Grau de parentesco dos migrantes de retorno, de última etapa, efeito indireto,

\begin{tabular}{|c|c|c|c|}
\hline \multicolumn{4}{|c|}{ 2010, Seridó } \\
\hline Grau de parentesco & $\begin{array}{l}\text { Frequência } \\
\text { Absoluta }\end{array}$ & $\begin{array}{l}\text { Frequência } \\
\text { Relativa }\end{array}$ & $\begin{array}{c}\text { Frequência Relativa } \\
\text { acumulada }\end{array}$ \\
\hline $\begin{array}{l}\text { Filho(a) do responsável e } \\
\text { do cônjuge }\end{array}$ & 628 & $29 \%$ & $29 \%$ \\
\hline $\begin{array}{l}\text { Cônjuge ou } \\
\text { companheiro(a) de sexo } \\
\text { diferente }\end{array}$ & 446 & $21 \%$ & $50 \%$ \\
\hline $\begin{array}{l}\text { Pessoa responsável pelo } \\
\text { domicílio }\end{array}$ & 379 & $18 \%$ & $67 \%$ \\
\hline $\begin{array}{l}\text { Filho(a) somente do } \\
\text { responsável }\end{array}$ & 320 & $15 \%$ & $82 \%$ \\
\hline Neto(a) & 144 & $7 \%$ & $89 \%$ \\
\hline Enteado(a) & 61 & $3 \%$ & $91 \%$ \\
\hline Genro ou nora & 26 & $1 \%$ & $93 \%$ \\
\hline Convivente & 24 & $1 \%$ & $94 \%$ \\
\hline $\begin{array}{l}\text { Pai, mãe, padrasto ou } \\
\text { madrasta }\end{array}$ & 21 & $1 \%$ & $95 \%$ \\
\hline Irmão ou irmã & 7 & $0 \%$ & $95 \%$ \\
\hline Outros & 110 & $5 \%$ & $100 \%$ \\
\hline
\end{tabular}


Considerações finais:

Diante de todas as informações apresentadas e expectativas iniciais do trabalho os dados não apresentaram os padrões esperados, pois diante da pequena população avaliada esperava-se uma maior variância nos dados o que poderia resultar em perfis totalmente diferentes. Todavia, os dados não apresentaram tal variância resultando em perfis parecidos, mas mesmo assim ainda foram constatadas algumas informações que seguem abaixo.

Os resultados dos dois efeitos juntos são bem explicativos e possui médias que não divergem muito de cada efeito em específico. Contatou-se um grande número, na população dos dois efeitos, de pessoas em idade economicamente ativas, uma quase totalidade de residentes em área urbana, um baixo nível de escolarização, Tem como última etapa migratória, principalmente, a cidade de Natal, Residiam na data do Censo, em maioria, em Caicó, 23\% deles recebem algum tipo de benefícios proveniente de programas de transferência de renda do governo federal, majoritariamente solteiros ou casados e mais da metade deles são do efeito direto.

Para o efeito direto observa-se que pertencem, em sua maioria, às classes de responsáveis pelo domicílio e cônjuge, possuem idade média entre 30 e 34 anos, são mulheres, possuem maior escolarização. Já para o efeito indireto verificou-se uma idade média entre os 20 e 24 anos, são homens, porém existe uma feminização nas idades economicamente ativas, possuem menor nível de instrução e pertencem às classes de filhos ou cônjuge.

Percebeu-se que para os dois efeitos o cônjuge é um elemento muito importante, pois para os dois efeitos manteve um peso considerável. Manteve-se em segundo lugar em ambas as análises.

Os dados obtidos são interessantes e na área educacional alarmantes, graças ao baixo nível de instrução. A partir de estudos como esse espera-se que seja levada as pautas das discussões estas populações e suas condições de vida, pois se faz necessário a reflexão dos dados para uma possível formulação de políticas sociais que possam atingir esse nicho da população. 
Referências:

CARVALHO, José; RIBEIRO, José. A imigração para Minas Gerais no período de 1981/1991, com especial enfoque na migração de retorno. Rev. Bras. Estudos Pop. Brasília, 16. n. 1/2 jan./dez. 1999.

CUNHA, Priscila. Imigrantes em Parnamirim/RN: Uma análise a partir do retorno migratório. Dissertação (Mestrado). Departamento de Demografia e Ciências Atuariais, DDCA, UFRN, 2016.

GARCIA, Ricardo Alexandrino; RIBEIRO, Adriana de Miranda. Movimentos migratórios em Minas Gerais: efeitos diretos e indiretos da migração de retorno- 19701980, 1981 1991, 1990-2000, em Revista Brasileira de Estudos Populacionais, São Paulo, Vol. 22, $\mathrm{N}^{\circ} 1$. . (2005),

GOLGHER, André Braz. Fundamentos da Migração. Centro de Desenvolvimento e Planejamento Regional, Cedeplar, UFMG. Belo Horizonte, MG, 2004.

MAGALHÃES, Marisa. O paraná e suas regiões nas décadas recentes: as migrações que também migram. Tese (Doutorado). Centro de Desenvolvimento e Planejamento Regional, Cedeplar, UFMG, 2003

OLIVEIRA, Kleber; Jannuzzi, Paulo. Motivos para migração no Brasil e retorno ao nordeste padrões etários, por sexo e origem/destino. São Paulo Em Perspectiva, Vol. 19, n. 4, p. 134-143, 2005.

QUEIROZ, Silvana; BAENINGER, Rosana. Migração de retorno para o Ceará: tendências dos anos 2000. VI Encontro Economia do Ceará, Fortaleza: Ceará, 2010

RIBEIRO, José; CARVALHO, José; WONG, Laura . Efeitos demográficos da migração de retorno: uma proposta metodológica. X Encontro Nacional de Estudos Populacionais, 1996. ABEP, 1996.

RIBEIRO, José; CARVALHO, José; WONG, Laura . Migração de retorno: algumas possibilidades de mensuração. X Encontro Nacional de Estudos Populacionais, 1996. ABEP, 1996. 